\title{
Documentos*
}

\section{Trinta por trinta: dimensões da pós-graduação em educação}

\author{
Carlos Roberto Jamil Cury \\ Pontifícia Universidade Católica de Minas Gerais,Programa de Pós-Graduação em Educação
}

\author{
Datas. Mas o que são datas? \\ Datas são pontas de icebergs.
}

Bosi, 1992, p. 19

1977: o país assiste à imposição do "pacote de abril" pelo general Geisel; morre Elvis Presley; Erasmo Dias invade a Pontifícia Universidade Católica de São Paulo (PUC-SP) ao proibir o Encontro Nacional de Estudantes; Augusto Boal escreve a peça Mulheres de Atenas; o Brasil adota o divórcio; o Corinthians conquista o título de campeão paulista; a Espanha reconhece o Partido Comunista (PC); é lida a Carta aos brasileiros assinada por Goffredo Telles Jr. e muitos outros signatários; sai a $2^{\mathrm{a}}$ edição de Educação e desenvolvimento social no Brasil, de Luiz Antonio Cunha; era diretor-geral da Coordenação de Aperfeiçoamento de Pessoal de Nível Superior (CAPES) o professor Darcy Closs, sendo Nei Braga ministro da Educação...

\footnotetext{
* Textos lidos na assembléia de abertura da $30^{\mathrm{a}}$ Reunião
} Anual da Anped, realizada em Caxambu, MG, no dia 7 de outubro de 2007.
Datas são pontos de luz sem os quais a densidade acumulada dos eventos pelos séculos dos séculos causaria um tal negrume que seria impossível sequer vislumbrar no opaco dos tempos os vultos dos personagens e as órbitas desenhadas pelas suas ações. A memória carece de nomes e de números. A memória carece de numes. (BOSI, 1992, p. 19)

1977: ano decisivo para a fundação da Associação Nacional de Pós-Graduação e Pesquisa em Educação (ANPEd).

Quando uma associação científica faz 30 anos de existência profícua e atuante, como a ANPEd, com um quadro significativo de realizações, é justo que ela os comemore.

Pela concepção vectorial de tempo as datas anunciam o ponto de partida daqueles regimes ou o seu ápice, ou, enfim, o momento exato em que cedem lugar ao período que os vai superar.

Pela concepção pontual e contingencial do tempo, que ninguém se deslumbre com a importância conferida a datas. Em torno dessas só há formigamento de interesses individuais, de paixões não raro inconfessadas que se acendem e se apagam... (BOSI, 1992, p. 26) 
O número de associados que, na década de 1970, se reunia em um hotel curitibano ou cearense passou a reunir-se em cidades universitárias como as das Universidade de São Paulo (USP), Universidade Federal do Rio Grande do Sul (UFRGS) ou Universidade Federal de Minas Gerais (UFMG) e, agora, as reuniões anuais se dão em cidades exibindo inscritos e participantes aos milhares e de todos os recantos do Brasil.

Para além de uma atuação intra-universitária, fomos protagonistas em memoráveis Conferências Brasileiras de Educação (CBEs), em lídimas lutas em prol da educação pública gratuita, leiga e de qualidade, especialmente em vista da Constituição da República de 1988 e seu antológico capítulo referente à educação. Nela, junto com outros parceiros coletivos e individuais, solidarizamo-nos na desconstrução da ditadura e na tarefa de construção da democracia. $\mathrm{Na}$ luta por uma relação virtuosa entre educação e cidadania, fomos parceiros na inscrição da educação como direito civil, como direito público subjetivo, como direito político e como o primeiro dos direitos sociais.

Batemo-nos por um financiamento crescente e vinculado a percentuais de impostos e pela titularidade do Estado como certificador de diplomas. Esses e outros documentos legais da educação teriam o condão de expressar o dever de Estado sendo que, mais tarde, eles haveriam de ser os amortecedores de impactos maiores quando meio mundo passou a postular a saída do Estado da salvaguarda de direitos juridicamente protegidos.

Pugnamos pela explicitação máxima desses direitos e deveres em uma Lei de Diretrizes e Bases da Educação Nacional em meados dos anos de 1990 inclusive com a defesa da formação sólida de profissionais da educação para toda a educação básica em nível superior. E, ao fim desses anos, por um plano nacional de educação que fosse um plano real: com diagnóstico, objetivos, metas, meios e recursos.

Em uma democracia, perdem-se espaços em um campo, ganham-se em outro, mas a bússola da $e d u$ cação como direito não perdeu seu sentido, ainda que apontando rotas de navegação difícil.
Datas são pontas de icebergs.

O navegador que singra a imensidão do mar bendiz a presença dessas pontas emersas, sólidos e geométricos, cubos e cilindros de gelo visíveis a olho nu e a grandes distâncias. Sem essas balizas naturais que cintilam até sob a luz noturna das estrelas, como evitar que nau se espedace de encontro às massas submersas que não se vêem? (Bosi, 1992, p. 19)

Nesses trinta anos muita coisa mudou: conhecemos a ditadura e a combatemos com muitos parceiros, continuamos a buscar as melhores vias de construção da democracia, passamos por sete presidentes da República, por 18 ministros da Educação e nos estados e municípios, sabe-se lá por quantos secretários de Educação...

Substituímos lendárias máquinas de escrever associadas ao bom e velho mimeógrafo pelo computador e a indefectível impressora. Os ventos da informatização secundarizaram o envio de pareceres pelo correio postal em favor do correio eletrônico. Temos página na rede mundial de computadores. Como qualquer associação civil sem fins lucrativos, a ANPEd obedece ao Código Civil e não cessa de defender a educação como um bem público em todos os seus níveis.

Somos parceiros da Sociedade Brasileira para o Progresso da Ciência (SBPC) e indicamos nomes para o Conselho Nacional de Educação (CNE).

O número de cursos e programas credenciados e reconhecidos pela CAPES, nesses anos todos, passou de 27 cursos de mestrado em 1984, para 86 mestrados em 2007. E, de 7 cursos de doutorado, em 1982, para 38 doutorados em 2007, em 88 programas (50 de mestrado, 2 de doutorado e 36 de mestrado e doutorado). O número de estudantes, mestrado e doutorado, aproxima-se dos 7.500. As publicações cresceram exponencialmente com múltiplos periódicos, livros e anais. Temos uma revista científica muito bem avaliada. Junto a ela, o número de revistas da área, qualificadas como disseminadoras de nossos estudos e pesquisas, ultrapassa três centenas.

A associação, que conheceu dez presidentes, foise diversificando em grupos de trabalhos, em um 
Fórum de Coordenadores (FORPRED), seja em nível nacional, seja em versões regionais. Espalhou-se por todo o país em pólos vice-presidenciais, montou um Comitê Científico e ganhou residência fixa.

$\mathrm{Na}$ formação de mestres e doutores, observa-se que, entre 1973 e 2006, a educação titulou 19.410 mestres (em 33 anos foram 588 mestres por ano) e 3.369 doutores (102 doutores por ano). Se em 1987 conferíamos o grau acadêmico de mestre para pouco mais de 200 estudantes e o grau de doutor para 14 doutorandos, em 2003 passamos a titular, por ano, mais de 1.800 mestres e 400 doutores.

Em 1986, tínhamos 561 professores permanentes no conjunto dos programas. Registrávamos ainda que desses 561 professores, 112 ainda eram mestres (na maioria em regime de doutoramento). Hoje somos perto de 1.600 professores atuando na pósgraduação em educação e 2.020 professores doutores ou livre-docentes.

Os temas enfrentam tão variados problemas quão múltiplos são os reptos, os desafios que a realidade nos traz e pretendem ser diagnosticados, pesquisados, analisados por 23 grupos de trabalho: História da Educação, Movimentos Sociais e Educação, Didática, Estado e Política Educacional, Educação Popular, Educação de Crianças de 0 a 6 anos, Formação de Professores, Trabalho e Educação, Alfabetização, Leitura e Escrita, Currículo, Política de Educação Superior, Educação Fundamental, Sociologia, Educação Especial, Educação e Comunicação, Filosofia da Educação, Educação de Jovens e Adultos, Educação Matemática, Psicologia da Educação, Afro-brasileiros e Educação, Educação Ambiental, Gênero e Sexualidade, Educação e Arte.

Nossos formados, conquanto boa parte vocacionados para a carreira universitária, continuam ocupando postos nas escolas da educação básica, em cargos de gestão e em pólos administrativos do aparelho de Estado e de outros núcleos da sociedade civil. Desses estudantes que passaram por nossas lides docentes, muitos e muitos são, hoje, nossos pares.

A área, pelos números apresentados, complexificou-se, seja pelo seu crescimento interno cada vez mais plural, seja pelo rigor e pela sofisticação dos processos avaliativos da CAPES, seja para cultivar a qualidade severamente mantida, seja para amparar individualmente o pesquisador com fomento e apoio do $\mathrm{CNPq}$ e das fundações de amparo à pesquisa dos estados.

Em outros termos, àquela simplicidade, reunida em um só hotel, sobrepôs-se uma organização complexa e diversificada. Ao analisar o risco permanente dos partidos políticos quando chegam a uma estrutura profissional e complexa, Roberto Michels aponta a perda do encantamento do nascedouro instituinte e a queda na rotina com o esquecimento da bússola de suas utopias. Será que nossa associação se vê obrigada, mutatis mutandis, a curvar-se a essa famosa lei de ferro da oligarquização apontada por Michels? Como manter nossos fins maiores, caso estejamos sob esse condicionamento?

Nesse momento, como não se lembrar do aviso dos poetas e cantores Marcos e Paulo Sérgio Valle?

\footnotetext{
Não confie em ninguém com mais de trinta anos

Não confie em ninguém com mais de trinta cruzeiros

O professor tem mais de trinta conselhos

Mas ele tem mais de trinta, oh ! mais de trinta,

Oh! mais de trinta

Não confie em ninguém com mais de trinta ternos

Não acredite em ninguém com mais de trinta vestidos

$\mathrm{O}$ diretor quer mais de trinta minutos

Pra dirigir sua vida, a sua vida
}

Por que esse aviso?

Em outros tempos, a idade de trinta anos apontava para quase um número cabalístico. Não era a data de entrada na vida pública, como ocorreu com Jesus Cristo. Era a idade de não ter mais sonhos. Era o fim do horizonte utópico. Era como "cair na real do sistema" aderindo ao status quo sociopolítico ou sair da vida pública e aposentando-se em um estranho solipsismo social, prisioneiro do ar poluído, como também nos aponta a mesma música.

É possível confiar em alguém com mais de trinta? Certamente não nos escapole o signo do huma- 
no. Não somos certeiros em tudo o que fizemos nesses 30 anos. No entanto, também não nos entregamos ao conformismo. Somos plurais, buscamos a participação interna, nossos arranjos indicam a busca de uma estrutura de poder calcada no diálogo e em vários escalões de direção com participação dos interessados.

Somos uma associação jovem. Mas, o que são 30 anos? $1,5 \%$ da era cristã? 5,9\% do encontro dos portugueses com os nativos? 25,4\% da República, 40\% do Manifesto dos Pioneiros da Educação Nova?

Nossa associação, tão jovem, tem muitos acertos e os resultados aí estão. Mas, como qualquer associação humana, por certo teve também seus equívocos: no conteúdo, no tom, na oportunidade, na hora. Se quem sabe faz a hora, é hora de nos revermos um pouco também por esse lado.

Nossa entidade, enquanto congregação de programas de pós-graduação, por meio desses, participa, com todos os graus de satisfação e de inconformidade, de uma etapa da organização da educação nacional. Bem ou mal, ela possui o distintivo da qualidade. Entendo que se trata, talvez o último, do nicho em que o sistema público detém uma hegemonia de qualidade. Com certeza problemática, essa qualidade tem a ver com um sistema nacional de pós-graduação do qual faz parte também um sistema de avaliação em que os pares ocupam papel significativo. Sou testemunha privilegiada, malgrado eu mesmo, do quanto pertencer ao "Sistema CAPES" é digno de reconhecimento no exterior e no país. Mas sei também o quanto é difícil alterar padrões consagrados como canônicos.

Por isso, é lícito também nos perguntarmos: teria o sistema nacional de pós-graduação se submetido de tal modo à lei férrea da oligarquização, já referida anteriormente, de modo que a busca de uma perenização funcional o tornaria insensível a uma participação mais intensiva dos pares? Essa submissão teria impedido formas mais equânimes e justas da gestão e da avaliação? Como conciliar organização e participação: eis um desafio permanente.

Pelo próprio caráter crítico da área, não poucas vezes pessimista, também somos obrigados a reconhecer: nossa educação vai mal.
Estamos longe de um acerto de contas com a democratização da educação infantil, por exemplo. Dos 345.341 docentes atuando nessa etapa da educação, 230.238 possuem o ensino normal médio, 97.895 possuem o ensino superior.

O ensino fundamental, obrigatório, gratuito e de nove anos, cujo acesso está em via de tornar-se cada vez mais universalizado, vê-se protegido com os mais diversos instrumentos de asseguramento - como obrigatoriedade, direito público subjetivo, controle de faltas, proteção jurídica pelo Estatuto da Criança e do Adolescente (lei n. 8.069/90) e pelo Código Penal (art. 246) e, sobretudo pelo Fundo Nacional de Valorização do Magistério e Desenvolvimento da Educação Básica (FUNDEB). Apesar disso, o país ainda conta com 1,961 milhão de crianças de 5 a 14 anos que tentam conciliar estudo e trabalho ou que abandonam a escola para complementar a renda da família. Permanece uma séria distorção idade/série bem como as avaliações manifestam baixas taxas de conclusão e discutível qualidade.

Por seu lado, dos 1.603.851 docentes atuantes no conjunto do ensino obrigatório, 811.112 exercem a docência nos quatro primeiros anos do ensino fundamental. Desses, 503.664 possuem apenas o ensino normal médio e 293.083 possuem o ensino superior.

$\mathrm{O}$ ensino médio, legalmente uma competência dos estados, constitucionalmente gratuito e também, por lei ordinária, "progressivamente obrigatório", não apresenta um quadro otimista. Do total dos matriculados, perto de $80 \%$ encontram-se dentro da faixa etária de 15 a 17 anos (7.335.485 alunos), mas com distorção na relação idade/série. Como entender que o país deixe fora da escola mais de dois milhões de jovens entre 15 e 17 anos?

E o que dizer de uma herança pesada que identifica 15 milhões de brasileiros com 15 anos ou mais sem escolaridade e sem acesso ao potencial trazido pela educação de jovens e de adultos? E os chamados analfabetos funcionais que beiram os 33 milhões de pessoas?

Essa situação agrava-se com a falta de inclusão digital para a maioria dos estudantes e de suas famí- 
lias sem desconsiderar o fato de muitos municípios serem carentes dessas indispensáveis ferramentas. $\mathrm{O}$ acesso às infovias torna-se outro obstáculo à construção de um novo espaço de cidadania. E nosso conhecimento de uma educação a distância com qualidade é ainda um desafio para nós.

E a situação dos docentes? Com os dados sobejamente sabidos a respeito de suas condições salariais, fica difícil não articular o desempenho precário do processo de aprendizagem com quem se vê obrigado a perfazer dois ou até três turnos de trabalho em vista da recomposição salarial. Como não enxergar aí um índice de subvalorização social do docente? Em contrapartida, vem-se tornando comum a inquietação dos pais com relação à ausência ou à falta de professores nos horários previstos. Deve-se pensar que as paralisações ou a falta de atração para a carreira sejam as duas faces mesma moeda e por isso os professores acabem desistindo (burn out) de ser professores?

E a nossa associação, com seus trinta anos, como se coloca diante de tal quadro?

É certo que o principal sujeito do dever da oferta qualificada de educação é o Estado. É claro que ele não cumpriu seu dever como deveria. É verificável que a sucessão histórica de discriminações e de desigualdades é a causa da permanência de situações intoleráveis e ela tem a ver com elites e segmentos importantes das classes dominantes.

Mas, hoje, nesta data festiva de 30 anos, cujo mote é Pesquisa e compromisso social, para não sucumbirmos ante o refrão da canção, cumpre nos interrogarmos: e nós? Nós que somos a elite intelectual da educação ou, por outra via mais aberta, e nós que optamos pela função de intelectuais? Urge perguntar: essa massa crítica conseguiu canalizar para os sistemas de ensino a melhoria da educação escolar? Conseguiu, assim agindo, preencher os requisitos próprios à condição de intelectuais, isto é, uma atuação pela palavra no espaço público que direcione para o melhor e para a maioria dos sujeitos do processo educacional?

Se erramos, onde erramos? Se acertamos, onde acertamos? Qual o peso relativo e proporcional de nossos equívocos e acertos ante essa situação? É pos- sível reavaliar nossa associação que tem como finalidade "a busca do desenvolvimento e da consolidação do ensino de pós-graduação e da pesquisa na área da Educação no Brasil"? E como um de seus objetivos: "Estimular as atividades de pós-graduação e pesquisa em educação para responder às necessidades concretas dos sistemas de ensino, das universidades e das comunidades locais e regionais, valorizando a cultura nacional e contribuindo para sua permanente renovação e difusa"?

Trinta anos, eis uma boa oportunidade para pensarmos também sobre isso.

Oportunidade é um momento propício para se rever, crescer e avançar. A origem etimológica de oportunidade dá o que pensar. Na base desse termo está a náutica. Sair de um porto e dirigir-se a outro é o roteiro de uma viagem que vê no próximo porto o momento propício para rever trajetos, riscar novos mapas e - por que não? - festejar a terra firme.

Oportunidade é passar por um porto. Por que não fazer desse porto, sempre provisório, uma porta para uma viagem melhor, mais bem sinalizada, mais segura?

Eis a cifra dos poetas, na mesma música:

Eu me desloco no tempo e no espaço

Passo a passo, faço mais um traço.

Faço mais um passo, traço a traço.

Acompanhar nosso processo e os nossos produtos é também acompanhar as "grandezas e misérias" desse sistema como um todo.

\footnotetext{
Eu meço a vida nas coisas que eu faço

E nas coisas que eu sonho e não faço

Eu me desloco no tempo e no espaço

Passo a passo, faço mais um traço.

Faço mais um passo, traço a traço.
}

E aqui quero fazer um passo e traçar um traço: se a área continua a ser avaliada sob uma concorrência regrada, não hesitemos em fazer da ANPEd um colegiado de solidariedade mútua e recíproca entre os programas. 
Se pensarmos em 2037, qual será o protagonismo de nossa associação ora completando 30 anos? Qual a interatividade entre o fogo da origem e a sabedoria da maturidade? Qual será a porta aberta, nos 30 anos vindouros, para um porto seguro da pós-graduação em educação?

\section{Referências bibliográficas}

MICHELS, Robert. Sociologia dos partidos politicos. Brasília: Ed. UnB, 1982.

BOSI, Alfredo. O tempo e os tempos. In: NOVAES, Adauto (Org.). Tempo e história. São Paulo: Cia. das Letras, 1992.

CARLOS ROBERTO JAMIL CURY, doutor em educação pela Pontifícia Universidade Católica de São Paulo (PUC-SP) e com pós-doutorado na França (Paris V e École des Hautes Études) é professor emérito da Universidade Federal de Minas Gerais (UFMG) e professor no Programa de Pós-Graduação em Educação da Pontifícia Universidade Católica de Minas Gerais (PUC$\mathrm{MG})$. Foi membro do Conselho Nacional de Educação (CNE), no período 1996-2004, e presidente da Coordenação de Aperfeiçoamento de Pessoal de Nível Superior (CAPES), no ano de 2003. Publicações mais importantes: Ideologia e educação brasileira (São Paulo: Cortez, 1978); Educação e contradição (São Paulo: Cortez, 1995; 6. ed.); “A relação educação-sociedade-estado pela mediação jurídico-constitucional" (em colaboração com José Silvério Baía Horta e Osmar Fávero, in: A educação nas constituintes brasileiras, 1823-1988. Campinas: Autores Associados, 1996, p. 5-30); Medo à liberdade e compromisso democrático: da LDB ao Plano Nacional de Educação (com José Silvério Baía Horta e Vera Lúcia Alves de Brito. São Paulo: Ed. do Brasil, 1977); Cidadania republicana e educação: Governo Provisório do Mal. Deodoro e Congresso Constituinte de 1890-1891 (Rio de Janeiro: DP\&A, 2001); Legislação educacional brasileira (Rio de Janeiro: DP\&A, 2001); Os fora de série na escola (Campinas: Autores Associados, 2005); "Direito à educação: direito à igualdade, direito à diferença”" (Cadernos de Pesquisa, n. 116, p. 245-262, jul. 2002.E-mail: crjcury.bh@terra.com.br

Recebido em outubro de 2007 Aprovado em novembro de 2007 